\title{
A theory of trade concessions
}

\author{
Mehmet Bac ${ }^{\mathrm{a}, *}$, Horst Raff ${ }^{\mathrm{b}}$ \\ ${ }^{a}$ Bilkent University, Department of Economics, Bilkent, 06533 Ankara, Turkey \\ ${ }^{\mathrm{b}}$ Indiana University, Department of Economics, Bloomington, IN 47405, USA
}

\begin{abstract}
We present a model of tariff disputes and concessions consisting of an infinitely repeated game under bilateral incomplete information. Given potential agreements to be reached through unilateral or reciprocal concessions, we find that an agreement involving reciprocal concessions is reached immediately if the discount factor is large and/or the volume of trade is small. Otherwise prior beliefs about country type matter: when both countries hold pessimistic priors, immediate reciprocal concessions still occur. Very different prior beliefs lead to an immediate unilateral concession of the pessimistic country, whereas optimistic priors coupled with low discount factors may generate delayed agreements. (C)1997 Elsevier Science B.V. All rights reserved.
\end{abstract}

Keywords: ; Repeated game; Tariff strategy; Incomplete information; Delay

JEL classification: F13

\section{Introduction}

International trade relations are generating new and severe conflicts ranging from bilateral disputes over trade in specific sectors to issues of multilateral trade, such as those addressed in the recent GATT round. A look at past trade disputes reveals that some were settled very quickly while others lasted for years. Besides differential delays in reaching agreement, resolutions of trade disputes varied also in the type of concessions that were made (unilateral or reciprocal). The purpose of this paper is to study the countries' incentives in settling trade disputes, provide

*Corresponding author. Tel.: (90-312) 2664190; fax: (90-312) 2664190; e-mail: bac@ bilkent.edu.tr. 
explanations for delay and take a first step toward identifying variables that may help us understand the type of concession that we observe.

Table 1 reports several examples of trade conflicts, starting with the AngloDutch trade war of 1614-1617 over trade in unfinished cloth and extending to a dispute between the United States and South Korea in 1986 over trade in television programs and movies. Both of these conflicts were settled through unilateral concessions, with the latter dispute being settled immediately while an agreement between Holland and England was reached only after three years. The conflicts between European nations at the end of the 19th century were also settled only after substantial delay, most of them through unilateral concessions. The more recent disputes between the European Community and the United States over trade in various sectors exhibited long delays in reaching agreement through both reciprocal and unilateral concessions.

In a detailed study of trade wars, Conybeare (1987) points to countries' incomplete information and the resulting need for learning about their partners' strengths as a major factor in explaining why many trade disputes take so long to settle, despite the obvious opportunity costs involved. In this paper we formalize this insight and examine how factors relating to the trading environment affect the way in which conflicts are settled. The trade literature has long recognized that an uncertain environment has an important effect on the conduct of trade policy. Feenstra and Lewis (1991), for instance, have studied incentive-compatible trade policies with private information about political pressure from lobby groups. Riezman (1991) demonstrates that unobservable tariffs can prevent countries from reaching free trade and may even lead to temporary trade conflicts if there are random terms of trade swings. Jensen and Thursby (1988, Jensen and Thursby, 1990) have analyzed one- and two-period tariff games where governments have private information about their objective function.

Our modeling of the information aspect is similar to that of Jensen and Thursby. However, we embed the information problem in a fully dynamic, infinitely repeated tariff game, which allows us to endogenize agreements and the way in which countries settle their disputes. Our tariff game starts with a conflict phase under two-sided incomplete information, followed by an agreement phase if countries reach one. All agreements are required to be self-enforcing. The countries will weigh the benefits associated with each potential agreement and choose their concession strategies accordingly. We demonstrate that the equilibrium is unique, if dominated equilibria are eliminated. The equilibrium of the overall game exhibits the types of dispute resolution identified in Table 1 (i.e. immediate reciprocal concessions, unilateral concessions, and delay), and shows how the type of resolution that occurs depends on the exogenous variables of the model, such as the discount factor, prior beliefs, the volume of trade, and industry cost characteristics.

The structure of our game and its analysis combine the use of self-enforcing agreements from the collusion and repeated game literature (see, for instance, 


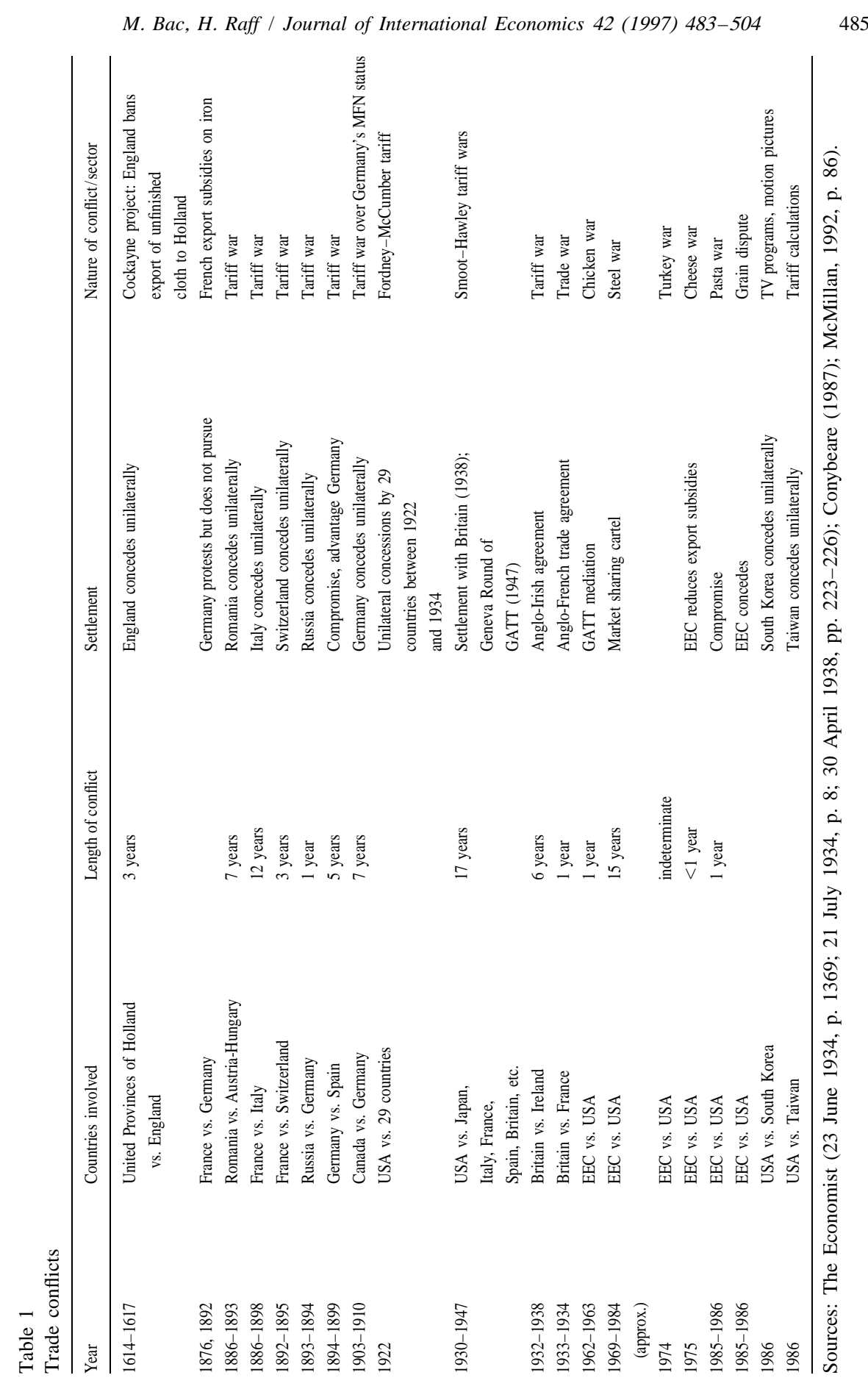


Harrington, 1991 and the many references in Tirole, 1988 and Fudenberg and Tirole, 1991) with the use of two-sided incomplete information bargaining models (see, for example, Chatterjee and Samuelson, 1987). The importance of incomplete information in conflict resolution, that we stress in this paper, is also examined in the law and economics literature in the context of negotiating out-of-court settlements (see Cooter and Rubinfield, 1989 for a survey of and references to that literature). In the context of international trade conflicts, several authors (e.g. Mayer, 1981; Riezman, 1982; Grossman and Helpman, 1993) have used bargaining models to derive predictions about how trade liberalizations would evolve. These models have the advantage of predicting a unique efficient trade agreement but they implicitly assume complete enforceability of international trade agreements. ${ }^{1}$ In our model countries worry about preventing defections from potential agreements, and hence take into account that potential agreements must be self-enforcing when choosing their concession strategies. As will become evident in our results, this leads to predictions that are different from those that would be obtained in a "standard bargaining" framework. On the other hand, there are studies (e.g. Dixit, 1987; Bagwell and Staiger, 1990; Ludema, 1991; Riezman, 1991) that explain when low tariffs are the result of implicit cooperation in repeated games, and agreements are thus self-enforcing. Yet, though not their purpose, these papers do not shed any light on the process of dispute settlement. In our paper, settlements are preceded by a conflict phase whose length is endogenous. Moreover, our study explains when countries reach different kinds of agreements.

The paper is organized as follows. Section 2 presents the overall tariff game and discusses the equilibrium concept. Section 3 defines the potential agreements and describes the countries' equilibrium behavior in the subgames associated with each agreement. The overall game is solved in Section 4 where we provide comparative statics results for different trade environments. Conclusions follow in Section 5.

\section{Description of the overall tariff game}

This section presents a two-country model of tariff concessions under two-sided incomplete information. At its heart is an infinitely repeated version of the familiar two-country optimum tariff game of Johnson (1953/54). In the Johnson game, while both consumers and producers in each country are price-takers, governments can influence the terms of trade through their choice of trade policy. We denote trade taxes by $x_{i}$ where $i=\mathrm{I}$,II represents the country. Each country chooses trade

\footnotetext{
${ }^{1}$ See Bagwell and Staiger (1990) and Staiger (1994) for an extensive discussion of this point, and Furusawa (1994) for an interesting model of bargaining to reach a self-enforcing agreement. A lack of enforcement of trade rules has often been cited as a major problem of the GATT and has therefore played an important role in the Uruguay Round. It has also been one of the reasons why the World Trade Organization as successor of the GATT was given larger enforcement powers.
} 
taxes so as to maximize social welfare. We let social welfare be given in indirect form as a continuous function of tariffs, $w_{i}\left(x_{i}, x_{j}\right)$. Country $i$ 's static best reply to the other country's tariff $x_{j}$ is implicitly defined by $\partial w_{i}\left(x_{i}, x_{j}\right) / \partial x_{j}=0$. We denote $i$ 's best-reply function by $x_{i}^{*}\left(x_{j}\right)$. The game starts from an inefficient level of protection described by the tariff pair $x^{\mathrm{H}}, x^{\mathrm{H}}$ (the "status quo" point). The corresponding status-quo welfare $w_{i}\left(x^{\mathrm{H}}, x^{\mathrm{H}}\right)$ is normalized to zero. We make the following standard assumptions:

Assumption 1. (i) $w_{i}$ is positive for all $x_{i}, x_{j} \in\left[0, x^{\mathrm{H}}\right)$; it is quasiconcave, increasing in $x_{i}$ up to the optimal tariff $x_{i}^{*}\left(x_{j}\right)$ and decreasing thereafter. (ii) Given $x_{i}, w_{i}$ is decreasing in $x_{j}$. (iii) For all $x_{j} \in\left[0, x^{\mathrm{H}}\right], x_{i}^{*}\left(x_{j}\right)$ is non-prohibitive, and $0<$ $x_{i}^{*}\left(x^{\mathrm{H}}\right)<x^{\mathrm{H}}$.

The static best-reply functions under this set of assumptions are illustrated in Fig. 1. Tariffs are strategic substitutes in the stage game played by two type $\mathrm{L}$ countries: country $i$ 's best reply $x_{i}^{*}\left(x_{j}\right)$ is a decreasing function of country $j$ 's tariff $x_{j}{ }^{2}$. The intersection of best-reply functions represents a static Nash equilibrium for type $\mathrm{L}$ countries.



Fig. 1. The stage game

${ }^{2}$ For further details on strategic policies in a two-country world, see the classic paper by Johnson (1953/54), or McMillan (1986) or Bagwell and Staiger (1990). The assumption that tariffs are strategic substitutes is not crucial for our general results below and therefore does not appear in the propositions of Section 4. 
Initially tariff policy is made under incomplete information in that each government knows its own indirect utility function but not that of the other government. We assume that each government can be of two types: a high-tariff type (type $\mathrm{H}$ ) and a low-tariff type (type L), distinguished by the form of their welfare and best-reply functions. The prior distribution on types $\pi_{i}=$ prob(country $i$ is of type $\mathrm{L}$ ) is common knowledge.

An example of this type of information problem is given by Jensen and Thursby (1990, p. 48): a low-tariff government chooses trade taxes to maximize the aggregate welfare of its citizens, whereas a high-tariff type's objective function reflects the interest of certain pressure groups. In an earlier paper, Jensen and Thursby (1988) show how a majority voting model with special interest groups can generate such objective functions. We model information incompleteness in a similar way, but specify that a type $\mathrm{H}$ country keeps the initial high tariff level $x^{\mathrm{H}}$ in all circumstances (see Fig. 1), whereas a type L country would potentially want to cut its trade taxes. While this formulation exaggerates the inflexibility of a high-tariff country, the model still generates the reputation-building behavior Jensen and Thursby show to be relevant in the context of incomplete information. The analytical advantage of our formulation is that it is easier to handle the information transmission process over time. For instance, any deviation from $x^{\mathrm{H}}$ reveals the same amount of information.

Throughout the paper, we will focus on the strategies and work with the welfare only of type L countries. This, of course, does not mean that both countries are known as type $\mathrm{L}$, but rather that the behavior of the type $\mathrm{H}$ is already transparent.

The tariff game described above is the stage game of our infinitely repeated overall game. The discount factor between periods is the same for both countries and denoted by $\delta$, where $0<\delta<1$. The overall game starts in period one with the "conflict phase", possibly followed by an "agreement phase". An agreement here is not a contract that can be enforced by a court of law, but rather an equilibrium of the subgame extending from the first concession. Our model thus satisfies a potentially important requirement of trade agreements: in the absence of effective mechanisms to enforce international contracts, such agreements should be selfenforcing. It also captures another feature of trade conflicts where the expected (endogenous) welfare in the post-agreement phase affects the countries' incentives to make concessions.

To keep track of the transmission of information between the countries, we decompose the countries' strategy sets in each stage game into two elements: (i) whether to make a concession and, if yes, then (ii) by how much to lower tariffs. That is, in each period, the type $\mathrm{L}$ of each country first decides independently on its mixed concession strategy denoted $\rho \in[0,1]$, a probability distribution over the two pure actions: to make or not to make a concession. The realization of $\rho$ is denoted $\hat{\rho}$. Once concession strategies are observed, a conceding country will also have to decide on how much to reduce its tariff. Given the tariff strategies, the countries enjoy their corresponding welfares and the game proceeds to the next 
period. ${ }^{3}$ Formally, let $a^{t}=\left(\left\{\hat{\rho}_{\mathrm{I}}^{t}, x_{\mathrm{I}}^{t}\right\} ;\left\{\hat{\rho}_{\mathrm{II}}^{t}, x_{\mathrm{II}}^{t}\right\}\right)$ be the actions observed in period $t$, and define the history of the play by $h^{t}=\left(a^{1}, a^{2}, \ldots, a^{t-1}\right)$. In the overall game, for $i=\mathrm{I}, \mathrm{II}$ indexing the countries, a mixed concession strategy is a sequence of maps, $\rho_{i}^{t}$, one for each period $t$, from possible histories into [0,1]. In any period, a tariff strategy of the type $\mathrm{L}$ is a mapping $x_{i}^{t}: h^{t} \times\{0,1\} \times\{0,1\} \rightarrow\left[0, x^{\mathrm{H}}\right]$ such that $x_{i}^{t} \in\left[0, x^{\mathrm{H}}\right)$ if country $i$ concedes, and $x_{i}^{t}=x^{\mathrm{H}}$ if it does not. The domain of $x_{i}$ is restricted to the realized value of the concession strategy because the decision on whether to make a concession precedes the one on the amount of the concession (the tariff strategy). Each country will use the opponent's previous (possibly mixed) concession strategy to update its beliefs via Bayes' rule. Recalling that $\hat{\rho}$ denotes the realized value of $\rho$, country $i$ 's belief in period $t$ is a function $\pi_{j}^{t}: t \rightarrow[0,1]$ such that, given $\pi_{j}^{t-1}$ and $\rho_{j}^{t-1}$,

$$
\pi_{j}^{t}=\left\{\begin{array}{cc}
1 & \text { if } \hat{\rho}_{j}^{s}=1 \text { for any } s<t ; \\
\frac{\pi_{j}^{t-1}\left(1-\rho_{j}^{t-1}\right)}{\pi_{j}^{t-1}\left(1-\rho_{j}^{t-1}\right)+\left(1-\pi_{j}^{t-1}\right)} & \text { if } \hat{\rho}_{j}^{s}=0 \text { for all } s<t .
\end{array}\right.
$$

Now for the definition of an agreement:

Definition 1. For $t>T$, we say that the strategy profile $\left(\left\{\rho_{\mathrm{I}}^{t}, x_{\mathrm{I}}^{t}\right\},\left\{\rho_{\mathrm{II}}^{t}, x_{\mathrm{II}}^{t}\right\}\right)$ is an agreement reached at date $T$ if it constitutes a perfect Bayesian equilibrium (PBE) of the game extending from date $t$, such that optimal concession strategies are always pure and remain constant, where at least one country plays $\left\{\rho_{\mathrm{I}}^{t}\right\}=$ $\{1,1,1, \ldots\}$.

An agreement in our model will fall into one of three broad classes, each corresponding to a particular subgame of the overall game. These three subgames, called RR, RN and $\mathrm{NR}^{4}$ themselves consist of infinitely repeated stage games. In accordance with the definition of an agreement, we require the equilibria of these subgames to be PBE. An agreement leading to the RR-game involves the play of

${ }^{3}$ The decomposition of strategies is technically useful because dealing with randomizations over a binary choice set \{concede, don't concede\} is easier than over a continuum of tariff strategies. Furthermore, the concession decision is crucial in determining the evolution of the overall game. Treating concession strategies separately highlights the transmission of information. A plausible alternative structure for the stage game, suggested by a referee, would be to have the concession and tariff strategies determined simultaneously. The discounted welfares corresponding to potential agreements we define in the next section and the tariff $x^{R}$ corresponding to a unilateral concession would not change. A difference, however, would occur during the period in which the conflict phase is resolved through bilateral concessions because tariff strategies would be determined under incomplete information, and an agreement would be reached one period later. This implies a change in the statement of the countries' expected discounted payoffs associated with the bilateral concessions outcome, $V_{i}^{R R}$ in Eq. (6) and Eq. (7). It is therefore possible that such a change would affect our conclusions.

${ }^{4} \mathrm{R}$ and $\mathrm{N}$ stand for "reducing" and "not reducing", respectively. 
PBE strategies according to which both countries reduce tariffs below $x^{\mathrm{H}}$. Both countries reveal their types, thus the RR-game is a repeated complete information game between two type L countries. As for the RN-game, it extends from the period where only country I concedes and makes a unilateral reduction, and the type L of country II pools with the type $\mathrm{H}$. The opposite outcome occurs in the NR-game: country II concedes and country I becomes the informed player. We will show later that no additional type-information is revealed in either the RN or the NR-game, so the informed country's optimal tariff strategy is to maintain $x_{\mathrm{H}}$ (and hence, $\rho=0$ ) indefinitely.

Let $V_{\mathrm{I}}^{t}$ and $V_{\mathrm{II}}^{t}$ denote respectively I's and II's expected discounted welfares as viewed from period $t$. A PBE of the overall game is a pair of sequences of concession strategies $\left\{\rho_{\mathrm{I}}^{t *}\right\},\left\{\rho_{\mathrm{II}}^{t *}\right\}$ and tariff strategies of type L countries such that, given $h^{t}$ and consistent beliefs $\left\{\pi_{\mathrm{I}}^{t}\right\}$ and $\left\{\pi_{\mathrm{II}}^{t}\right\}$,

$$
\begin{aligned}
& V_{\mathrm{I}}^{t}\left(\left\{\rho_{\mathrm{I}}^{t *}\right\},\left\{\rho_{\mathrm{II}}^{t *}\right\}\right) \geq V_{\mathrm{I}}^{t}\left(\left\{\rho_{\mathrm{I}}^{t}\right\},\left\{\rho_{\mathrm{II}}^{t *}\right\}\right) \text { for all }\left\{\rho_{\mathrm{I}}^{t}\right\} \\
& V_{\mathrm{II}}^{t}\left(\left\{\rho_{\mathrm{I}}^{t *}\right\},\left\{\rho_{\mathrm{II}}^{t *}\right\}\right) \geq V_{\mathrm{II}}^{t}\left(\left\{\rho_{\mathrm{I}}^{t *}\right\},\left\{\rho_{\mathrm{II}}^{t}\right\}\right) \text { for all }\left\{\rho_{\mathrm{II}}^{t}\right\}
\end{aligned}
$$

Tariff strategies are omitted for conciseness; they are implicit in Eq. (1) and Eq. (2). By definition of an agreement, the PBE concession strategies during the agreement phase can take only two values ( 1 or 0$)$; in the conflict phase they are drawn from the interval $[0,1]$. Of course, the overall game may exhibit an equilibrium in pure concession strategies. We shall then argue that an agreement is reached immediately.

\section{Analysis of potential agreements and subgames}

We proceed in this section with the analysis of the three potential subgames and define the agreements corresponding to each. As mentioned, each of these subgames is characterized by an infinitely repeated stage game with a particular information structure. The evolution of the conflict will determine which subgame will be reached, but this question is relegated to Section 4 .

Consider the stage game played under complete information and let us introduce the following notation for future reference. The symmetric, static Nash equilibrium tariff in the stage game where both players are of type $\mathrm{L}$ is denoted by $x^{\mathrm{E}}$, and the corresponding welfare by $\underline{w}=w\left(x^{\mathrm{E}}, x^{\mathrm{E}}\right)$. We denote the static best reply to $x^{\mathrm{H}}$ by $x^{\mathrm{R}}=x^{*}\left(x^{\mathrm{H}}\right)$, which is the tariff strategy of a type $\mathrm{L}$ country that concedes unilaterally. The welfare of the type $\mathrm{L}$ of country I playing against a type $\mathrm{H}$ is

\footnotetext{
${ }^{5}$ See Fudenberg and Tirole (1991) for an extensive treatment of the PBE concept. Basically, the concept requires that strategies be sequentially optimal given players' beliefs and that beliefs be updated according to Bayes' rule whenever possible (along the equilibrium path).
} 
represented by $w^{\mathrm{R}}=w_{\mathrm{I}}\left(x^{\mathrm{R}}, x^{\mathrm{H}}\right)=w_{\mathrm{II}}\left(x^{\mathrm{H}}, x^{\mathrm{R}}\right)$, where the last equality follows from the symmetry of the welfare functions. Finally, we have $w^{\mathrm{N}}=w_{\mathrm{I}}\left(x^{\mathrm{H}}, x^{\mathrm{R}}\right)=$ $w_{\mathrm{II}}\left(x_{\mathrm{R}}, x_{\mathrm{H}}\right)$, where $w^{\mathrm{N}}$ is the stage-game welfare of a type L country that enjoys the unilateral concession of its opponent. Throughout the paper, we shall assume

\section{Assumption 2.}

$$
w^{\mathrm{N}}>\underline{w} .
$$

Assumption 2 is illustrated in Fig. 1. It states that country I prefers the tariff pair $\left(x^{\mathrm{H}}, x^{\mathrm{R}}\right)$ and country II prefers $\left(x^{\mathrm{R}}, x^{\mathrm{H}}\right)$ to the static complete-information equilibrium $\left(x^{\mathrm{E}}, x^{\mathrm{E}}\right)$. That is, under incomplete information, a country will keep its status-quo tariff $x^{\mathrm{H}}$ if it is convinced that the other country will concede, but will reduce its tariffs if it is sufficiently likely that the other country will not. If Assumption 2 does not hold, the two types always "separate". Under Assumption 2 , however, equilibria may involve reputation building and delay, and interesting questions like "under what conditions do we observe delay?" and "for how long will a conflict last?" arise.

The first subgame we focus on is the RR-game (it is common knowledge that both countries are of type L). Let $p=\left(\left\{x_{\mathrm{I}}^{t}\right\},\left\{x_{\mathrm{II}}^{t}\right\}\right)$ be a path consisting of a pair of infinite sequences of tariff strategies $x_{i}^{t} \in\left[0, x^{\mathrm{H}}\right]$. Then, country $i$ 's discounted welfare associated with the path $p$ is

$$
V_{i}(p)=\sum_{t=1}^{\infty} \delta^{t-1} w_{i}\left(x_{\mathrm{I}}^{t}, x_{\mathrm{II}}^{t}\right)
$$

Let the path $p_{0}=\left(\left\{x^{\mathrm{E}}\right\},\left\{x^{\mathrm{E}}\right\}\right)$ be the punishment path, consisting of the repeated play of the static Nash equilibrium tariff $x^{\mathrm{E}}$ ad infinitum. It is well known that the strategies along $p_{0}$ form a subgame perfect equilibrium (SPE) of the RR-game, hence a PBE and a potential agreement. Our approach is to focus on equilibria that yield a welfare pair on the welfare possibility frontier, that is, the set of (constrained) optimal welfare pairs as a function of the discount factor. Allowing for dominated agreements as expected outcomes of the RR-game only enlarges the set of potential outcomes, but these outcomes can easily be characterized in terms of the equilibrium classification to be introduced in Section 4. Here we consider the symmetric, efficient PBE, which can be interpreted as the "focal equilibrium" of the RR-game.

A PBE of the RR-game is characterized by the concession strategies $\rho_{i}^{t}=1$ for

${ }^{6}$ Our justification for picking the efficient symmetric equilibrium as the focal point is twofold: first, in a symmetric game the equilibrium should not change if we just exchange the names of the two countries; this property is satisfied only for symmetric equilibria. Second, we would like to focus on ex ante efficient equilibria, since the model does not provide any economic intuition for why countries should play ones that are not. Instead we concentrate on inefficiencies that arise in the process of playing ex ante undominated equilibria. 
$i=\mathrm{I}, \mathrm{II}$ and the two paths defined above, $p$ the initial path and $p_{0}$ the punishment path, such that no country has any incentive to deviate, be it from the path $p$ or the path $p_{0}$ that is followed. If any country deviates from $p$, the play switches to the path $p_{0}$. Let $\bar{w}=w(\bar{x}, \bar{x})$, where $\bar{x}$ maximizes $w(x, x)$ subject to

$$
\bar{w} \geq(1-\delta) w_{i}\left(x_{i}^{*}(\bar{x}), \bar{x}\right)+\delta \underline{w} .
$$

Eq. (4) is the "subgame-perfection" constraint (explained in the sequel), and $\bar{x}$ is the most cooperative tariff that can be a PBE strategy for a given $\delta$. We now introduce Agreement RR.

Agreement RR. Countries initially follow the path $p$ along which tariffs are $\bar{x}$. The game proceeds on this path as long as no deviation occurs. Any deviation from $p$ leads to the punishment path $p_{0}$ being followed indefinitely.

It is easy to verify that Agreement RR is self-enforcing, that is, the strategies described therein form a PBE. The left-hand side of Eq. (4) represents the maximum welfare that can be supported through the threat of reverting to the path $p_{0}$, along which the static Nash equilibrium is repeated forever. The country deviating from $p$ obtains $w_{i}\left(x_{i}^{*}(\bar{x}), \bar{x}\right)$ in the actual period and $\underline{w}$ thereafter. The sum of the two, appropriately discounted, appears on the right-hand side of Eq. (4). Thus, if Eq. (4) is satisfied, no country will have any incentive to deviate from $\bar{x}$. Finally, since the strategies along the punishment path $p_{0}$ form a PBE, the strategies described in Agreement RR constitute a PBE as well. We have $w\left(x_{i}^{*}(\bar{x}), \bar{x}\right)>\bar{w}>\underline{w}$, and the tariff $\bar{x}$ appearing in Agreement RR maximizes $w(x, x)$ under the subgame-perfection constraint (Eq. (4)).

Consider now one of the two other potential subgames, for example, the NR-game (the analysis of the RN-game is similar). At the beginning of this subgame, beliefs are respectively $\pi_{\mathrm{II}}=1$ and $\pi_{\mathrm{I}} \in[0,1)$, thus country $\mathrm{I}$ is the informed player. In Proposition 1 we shall refer to Eq. (5), which states that country I's average welfare under the tariffs $x_{\mathrm{I}}=x^{\mathrm{H}}, x_{\mathrm{II}}=x^{\mathrm{R}}$ (with corresponding concession strategies $\left.\rho_{\mathrm{I}}=0, \rho_{\mathrm{II}}=1\right)$ is strictly higher than the average welfare it obtains under Agreement RR.

$$
w^{\mathrm{N}}>\bar{w} .
$$

Agreement NR. Country II reduces its tariff to $x^{\mathrm{R}}$ while country I keeps its tariff at $x^{\mathrm{H}}$. These tariffs will prevail indefinitely. It is understood that if country I ever reduces its tariff (deviates to $\rho_{\mathrm{I}}=1$ ) this agreement is replaced by Agreement RR, but that country II's deviations are ignored.

Proposition 1. Under Eq. (5), the strategies described in Agreement NR constitute a PBE of the NR-game. On the other hand, Agreement RR applies if Eq. (5) does not hold.

${ }^{7}$ Note that Eq. (5) implies Assumption 2 because $\bar{w} \geq \underline{w}$, but the reverse is not true. 
Proof. It is common knowledge that country II is of type L, thus its threat to keep its tariff at $x^{\mathrm{H}}$ is not credible, and ruled out by the "perfectness" requirement. Country II's best tariff strategy is thus $x^{\mathrm{R}}$ as long as $x_{\mathrm{I}}=x^{\mathrm{H}}$. Since both types of country I play $\rho_{\mathrm{I}}=0$, country II's beliefs remain constant along the path described in Agreement NR. Nor will country I deviate from $\left(\rho_{\mathrm{I}}=0, x_{\mathrm{H}}\right)$, because otherwise it reveals its type and the game collapses to the RR-game, which leads to Agreement RR. Under Eq. (5), this deviation yields the average welfare $\bar{w}<w^{N}$ for country I. Thus the strategies described above are optimal for all periods where Agreement NR applies, and beliefs are consistent with equilibrium strategies. We conclude that the strategies described in Agreement NR form a PBE. Clearly, this is not true if Eq. (5) does not hold. Q.E.D.

Exchanging the positions of the two countries in Agreement NR yields trivially Agreement RN for the RN-game. In both the NR and the RN-game, the conceding country reduces its tariff, while the informed country keeps $x^{\mathrm{H}}$. The reason why this situation persists is that the informed country's type cannot be verified; there is a probability (however small) that the informed country is of type H. Since the concept of PBE effectively eliminates empty threats of the conceding country of the form "I will reset my tariffs to $x^{\mathrm{H}}$ if you (the informed country) do not reduce your tariffs now", the conceding country is bound to play the game as if it were facing a type-H country.

The necessary condition for Agreement RN or NR to be reached is Eq. (5), and one of the crucial factors determining whether Eq. (5) holds is the discount factor through its effect on $\bar{w}$. To see the impact of $\delta$ on $\bar{w}$, we rearrange Eq. (4) and obtain

$$
\delta(\bar{w}) \geq \frac{w_{i}\left(x_{i}^{*}(\bar{x}), \bar{x}\right)-\bar{w}}{w_{i}\left(x_{i}^{*}(\bar{x}), \bar{x}\right)-\underline{w}} .
$$

Eq. (6) defines the set of discount factors $\delta \in[\delta(\bar{w}), 1]$ that support a given average welfare $\bar{w}$ as a PBE outcome of the RR game. Alternatively, we can define the maximum $\bar{w}$ that can be supported given the discount factor. This is obtained from Eq. (6) holding with equality. It follows that the lower is the discount factor, the lower is the maximum welfare that can be supported in Agreement RR, and thus the more likely Eq. (5) is to hold. In particular, $\bar{w} \rightarrow \underline{w}$ as $\delta \rightarrow 0$, and Eq. (5) will actually hold.

Having defined the three potential agreements, we close this section with the following proposition, which is a direct implication of the fact that the equilibria associated with all agreements are self-enforcing.

Proposition 2. In no equilibrium of the overall game are Agreements $R N$ and NR ever renegotiated for Agreement RR. Nor is Agreement RR ever replaced by Agreement $R N$ or NR in any equilibrium.

We have thus specified the expected average welfares of the two countries for 
the three potential agreements. Given these welfares, we proceed backwards to the analysis of the conflict phase.

\section{The conflict phase and potential agreements}

Since countries are forward-looking in choosing their concession strategies during the conflict phase, how the expected welfares associated with the RR-game compare with those of the NR- or RN-game is a critical issue. This is explicit in Eq. (7) and Eq. (8), the expressions for the countries' expected discounted welfares at the outset of the overall game. Recall that we are concerned only with the behavior of the type L, and that $\pi_{\mathrm{I}}^{1}$ and $\pi_{\mathrm{II}}^{1}$ denote the prior beliefs of country II and I, respectively.

$$
\begin{aligned}
V_{\mathrm{I}}^{1}= & \rho_{\mathrm{I}}^{1}\left[\rho_{\mathrm{II}}^{1} \pi_{\mathrm{II}}^{1} V_{\mathrm{I}}^{R R}+\left(1-\rho_{\mathrm{II}}^{1} \pi_{\mathrm{II}}^{1}\right) V_{\mathrm{I}}^{R N}\right] \\
& +\left(1-\rho_{\mathrm{I}}^{1}\right)\left[\rho_{\mathrm{II}}^{1} \pi_{\mathrm{II}}^{1} V_{\mathrm{I}}^{N R}+\left(1-\rho_{\mathrm{II}}^{1} \pi_{\mathrm{II}}^{1}\right) \delta V_{\mathrm{I}}^{2}\right], \\
V_{\mathrm{II}}^{1}= & \rho_{\mathrm{II}}^{1}\left[\rho_{\mathrm{I}}^{1} \pi_{\mathrm{I}}^{1} V_{\mathrm{II}}^{R R}+\left(1-\rho_{\mathrm{I}}^{1} \pi_{\mathrm{I}}^{1}\right) V_{\mathrm{II}}^{R N}\right] \\
& +\left(1-\rho_{\mathrm{II}}^{1}\right)\left[\rho_{\mathrm{I}}^{1} \pi_{\mathrm{I}}^{1} V_{\mathrm{II}}^{N R}+\left(1-\rho_{\mathrm{I}}^{1} \pi_{\mathrm{I}}^{1}\right) \delta V_{\mathrm{II}}^{2}\right]
\end{aligned}
$$

In the expression of $V_{i}{ }^{1}$, the squared bracket following $\rho_{i}{ }^{1}$ represents country $i$ 's expected discounted welfare from its immediate unilateral concession, and the one following $\left(1-\rho_{i}^{1}\right)$, from keeping the status-quo tariff in period one. Combinations of $\mathrm{R}$ and $\mathrm{N}$ appear in the superscript of $V_{i}$ to denote country $i$ 's expected discounted welfare from the three potential agreements, RR, RN and NR. The expressions of $V_{i}^{\mathrm{RR}}, V_{i}^{\mathrm{RN}}$ and $V_{i}^{\mathrm{NR}}$ are obtained as follows. If both countries realize a concession in the first period, the RR-game begins and the countries obtain the symmetric average payoff $\bar{w}(\delta)$ under Agreement RR. These arguments can be combined to yield

$$
V_{\mathrm{I}}^{R R}=V_{\mathrm{II}}^{R R}=\sum_{t=1}^{\infty} \delta^{t-1} \bar{w}(\delta)=\frac{\bar{w}(\delta)}{1-\delta} .
$$

Since concession strategies may be mixed, when and which agreement the countries will reach is uncertain. As Eq. (7) and Eq. (8) show, the probability of reaching Agreement RR immediately, with a little abuse of notation, is $\rho_{\mathrm{I}}^{1} \rho_{\mathrm{II}}^{1} \pi_{\mathrm{II}}^{1}$ from the perspective of country I, and $\rho_{\mathrm{II}}^{1} \rho_{\mathrm{I}}^{1} \pi_{\mathrm{I}}^{1}$ from the perspective of country II. If only country I concedes, the game collapses to the RN-game, and Agreement $\mathrm{RN}$ applies. In this case, we have

$$
V_{\mathrm{I}}^{R N}=\sum_{t=1}^{\infty} \delta^{t-1} w^{\mathrm{R}}=\frac{w^{\mathrm{R}}}{1-\delta}
$$


and

$$
V_{\mathrm{II}}^{R N}=\sum_{t=1}^{\infty} \delta^{t-1} w^{\mathrm{N}}=\frac{w^{\mathrm{N}}}{1-\delta}
$$

Eq. (10) and Eq. (11) can easily be adapted to the symmetric case, the NR-game: we have $V_{\mathrm{I}}^{R N}=V_{\mathrm{II}}^{N R}$, and $V_{\mathrm{I}}^{N R}=V_{\mathrm{II}}^{R N}$. Last, if no concession occurs in the first period, beliefs are updated and the game proceeds to period two with expected discounted welfares given by $\delta V_{\mathrm{I}}^{2}$ and $\delta V_{\mathrm{II}}^{2}$, respectively. The status-quo tariffs cannot persist indefinitely, however:

Proposition 3. An agreement will be reached at a finite date $T$ with probability one, if at least one country is of type $L$.

Proof. Suppose, on the contrary, that $\left\{\rho_{i}^{t}\right\}=\{0,0, \ldots\}$ for $i=\mathrm{I}, \mathrm{II}$ and $t=$ $1,2,3, \ldots$, together with consistent beliefs $\pi_{i}^{t}=\pi_{i}^{1}$ if $\hat{\rho}_{i}^{t-1}=0$ and $\pi_{i}^{t}=1$ if $\hat{\rho}_{i}^{t-1}=1$ form a PBE. Let country I be of type L. Given country II's prescribed strategy $\rho_{\mathrm{II}}^{T}=0$, country I's expected discounted welfare from deviating (conceding) at date $T$ is $w^{\mathrm{R}} /(1-\delta)$, whereas playing $\rho_{\mathrm{I}}^{t}=0$ for $t \geq T$ yields $\delta V_{\mathrm{I}}^{T+1}$. If, as assumed, the latter strategy is optimal, then $V_{\mathrm{I}}^{T}=\delta V_{\mathrm{I}}^{T+1}$. However, since $\rho_{\mathrm{II}}^{T}=0$, the subgames extending from periods $T$ and $T+1$ have exactly the same structure, hence $V_{\mathrm{I}}^{T}=V_{\mathrm{I}}^{T+1}$. This leads to $V_{\mathrm{I}}^{T}(1-\delta)=0$, or $V_{\mathrm{I}}^{T}=0$. Thus, deviating in period $T$ enhances the welfare of country I, a contradiction. Q.E.D.

We can now proceed to characterize the PBE of the overall game, starting with pure concession strategies. Any pair of sequences of zeros and ones that satisfies the consistency requirement of beliefs is a candidate for a PBE in pure concession strategies. If strictly dominated equilibria are ruled out, however, Proposition 4 below stipulates that in any PBE involving the play of pure concession strategies, at least one of the countries concedes (an agreement is reached) immediately.

Proposition 4. If $\left(\left\{\rho_{\mathrm{I}}^{1}\right\},\left\{\rho_{\mathrm{II}}^{1}\right\}\right)$ form a PBE in pure concession strategies, then either $\left\{\rho_{i}^{1}\right\}=\{1,1, \ldots\}$ for $i=\mathrm{I}$,II, or $\left\{\rho_{i}^{1}\right\}=\{0,0, \ldots\}$ and $\left\{\rho_{j}^{1}\right\}=\{1,1, \ldots\}$ for $i \neq j$.

Proof. Since play in the agreement phase proceeds through pure concession strategies, it is sufficient to show that an agreement will be reached in period one if only pure concession strategies are allowed. Suppose, then, that Agreement RN is signed at some date $t>1$. At the beginning of period $t$ (before concession

\footnotetext{
${ }^{8}$ An exception arises if we allow the countries to play strictly dominated equilibria. We thus assume that given the values of relevant parameters, if there are two equilibria such that one yields ex ante both countries a higher expected discounted welfare than the other, countries play the equilibrium associated with higher expected discounted welfares.
} 
strategies are played) beliefs are equal to priors: $\pi_{i}^{t}=\pi_{i}^{1}$ for $i=$ I,II. This implies that the structure of the game at date $t$ is exactly the same as in the outset. Country I will deviate from the proposed equilibrium strategies and concede in period one; doing so will enhance its welfare by $\left.\sum_{i=1}^{t-1}\right] \delta^{t-1} w^{\mathrm{R}}$, and Agreement RN will be reached without delay. The same argument can be used for Agreement NR. Finally, proceeding in pure defection strategies to reach Agreement RR at some future date is strictly dominated by reciprocal concessions in period one if $\delta<1$ (because both parties avoid discounting the corresponding gains). Q.E.D.

The question of when the countries reach an agreement immediately is studied below. Let us define $\delta_{\mathrm{c}}$, a critical value of the discount factor, by

$$
\bar{w}\left(\delta_{\mathrm{c}}\right)=w^{\mathrm{N}} .
$$

That is, if $\delta=\delta_{\mathrm{c}}$, the highest welfare that can be supported in Agreement RR is just equal to $w^{\mathrm{N}}$, the average welfare that country I obtains under Agreement NR (or country II obtains under Agreement RN). Eq. (5) holds for $\delta<\delta_{\mathrm{c}}$, and for discount factors greater than $\delta_{\mathrm{c}}$ countries will prefer Agreement RR. Proposition 5 below characterizes PBE of the overall game in pure concession strategies.

\section{Proposition 5. Assume Assumptions 1 and 2.}

Case (1): $\left(\delta \geq \delta_{\mathrm{c}}\right)$. A unique PBE exists in which the countries reach Agreement $R R$ immediately through reciprocal concessions. The corresponding strategies are: $\left\{\rho_{i}{ }^{1 *}\right\}=\{1,1, \ldots\}$ and $\left\{x_{i}^{1 *}\right\}=\{\bar{x}, \bar{x}, \ldots\}$ for $i=\mathrm{I}, \mathrm{II}$, where $\bar{x}$ is defined through Eq. (4) and beliefs form the sequence $\left\{\pi_{i}^{1}\right\}=\left\{\pi_{i}^{1}, 1,1, \ldots\right\}$.

Case (2): $\left(\delta<\delta_{\mathrm{c}}\right)$. There exists a critical region of priors defined by the function $\bar{\pi}(\delta):\left(0, \delta_{\mathrm{c}}\right] \rightarrow[0,1]$, such that, if $\pi_{i}^{l} \leq \bar{\pi}(\delta)$ for $i=\mathrm{I}$,II, the equilibrium is as described in case (1), that is, Agreement RR is reached immediately. On the other hand, if $\pi_{i}^{1} \leq \bar{\pi}(\delta)<\pi_{j}^{1}$, then Agreement $R N$ or NR is reached immediately through unilateral concessions. The corresponding strategies are $\left\{\rho_{i}^{1 *}\right\}=$ $\{0,0, \ldots\},\left\{x_{i}^{1 *}\right\}=\left\{x^{\mathrm{H}}, x^{\mathrm{H}}, \ldots\right\}$ for country $i$, and $\left\{\rho_{j}^{1 *}\right\}=\{1,1, \ldots\},\left\{x_{j}^{1 *}\right\}=$ $\left\{x_{\mathrm{R}}, x_{\mathrm{R}}, \ldots\right\}$ for country $j$.

Corresponding sequences of beliefs are $\left\{\pi_{i}^{1 *}\right\}=\left\{\pi_{i}^{1}, \pi_{i}^{1}, \ldots\right\}$ and $\left\{\pi_{j}^{1 *}\right\}=$ $\left\{\pi_{j}^{1}, 1,1, \ldots\right\}$. No PBE in pure concession strategies exist if $\pi_{i}^{1}>\bar{\pi}(\delta)$ for $i=\mathrm{I}$,II.

\section{Proof. See Appendix A.}

We now sum up and sharpen the results obtained so far. With probability one, Agreement RR emerges without delay in either one of the two cases: (i) the discount factor is high $\left(\delta \geq \delta_{\mathrm{c}}\right.$ ), (ii) the discount factor is low and both prior beliefs do not exceed a critical level associated with this discount factor. Case (ii) is depicted in Fig. 2 by the shaded area. The inclusion of incomplete information has no impact on the pattern of tariffs in these two cases. On the other hand, very asymmetric prior beliefs coupled with low discount factors may lead to Agreement 




Fig. 2. Equilibria for $\delta<\delta_{\mathrm{c}}$

RN or Agreement NR. . Countries that hold "pessimistic" prior beliefs make unilateral concessions on tariffs. This is intuitive: if it is very likely that the other country is of type $\mathrm{H}$, it is not worthwhile waiting for its concession. As Proposition 6 shows, however, the foregoing discussion does not imply that no country will concede if both are "optimistic" initially.

Proposition 6. Under Assumptions 1 and $2, \delta<\delta_{\mathrm{c}}$ and $\bar{\pi}(\delta)<\pi_{i}^{1}<1$ for $i=\mathrm{I}$,II. A unique PBE initially in mixed concession strategies $\left(\left\{\rho_{\mathrm{I}}^{t *}\right\},\left\{\rho_{\mathrm{II}}^{t *}\right\}\right)$ and a finite integer $T>1$ exist such that an agreement is reached at date $T$ with probability one.

Proof. See Appendix A.

The outcome described in Proposition 6 is a war of attrition. The necessary conditions for this outcome are a low discount factor and optimistic conjectures about types. A low discount factor reduces the incentives to reach Agreement RR because the highest average welfare that can be sustained through cooperation is low. It can even be lower than $w^{\mathrm{N}}$, the average welfare of a type $\mathrm{L}$ who conceals its type provided that the other country concedes. The usual interpretation of the discount factor is that of pure time preference, i.e. $\delta=e^{-r \Delta}$ where $\Delta$ is the length

\footnotetext{
${ }^{9}$ An additional implication of the assumption that a type-H country always imposes tariff $x^{\mathrm{H}}$ is that in Agreements NR and RN countries cannot coordinate as they do in Agreement RR on a more cooperative outcome with lower tariffs. This makes Agreement RR appear more attractive. We are grateful to a referee for pointing this out.
} 
of a period in which tariff strategies remain fixed, and $r$ is the rate of time preference. In our context, $r$ would be much affected by "public choice considerations" (election cycles, importance of unemployment and other urgent domestic economic problems, etc.). Our results thus can easily be reformulated using the negative relationship between $\delta$ and $r$ (or $\Delta$ ). ${ }^{10}$

If the discount factor is low but both prior beliefs are high, the countries conceal their types each hoping that the other will concede. However, the potential gains from pooling with the type $\mathrm{H}$ are unknown, hence countries hesitate between conceding and maintaining the status-quo tariff. The expected payoff from conceding in each period equals the expected payoff from "holding out", given the other country's random concession strategy. This indifference condition holds throughout the equilibrium path; concession strategies initially are completely mixed, until one country (or both) concedes as a result of these randomizations, or one country (or both) becomes so pessimistic about facing a type L country that it chooses a pure concession strategy at some finite period $T$.

We have characterized the PBE of the overall game in terms of the discount factor and prior beliefs. We now investigate the relationship between the parameters of the trade environment and the type of concession strategies that will be observed in equilibrium. The relevant condition that we need to interpret is Eq. (13), under which country I prefers to make a concession rather than to wait for one more period given that the type L country II will concede immediately: ${ }^{11}$

$$
\pi_{\mathrm{II}}^{1}\left(\bar{w}(\delta)-w^{\mathrm{N}}\right)+\left(1-\pi_{\mathrm{II}}^{1}\right) w^{\mathrm{R}}(1-\delta) \geq 0 .
$$

An equivalent condition holds for country II. Whether Eq. (13) is satisfied depends (for given $\delta, \pi_{\mathrm{I}}^{1}$ and $\pi_{\mathrm{II}}^{1}$ ) on the exogenous factors that affect the welfares $\bar{w}(\delta$ ), $w^{\mathrm{N}}$ and $w^{\mathrm{R}}$, each associated with different potential agreements.

Consider first an increase in $x^{\mathrm{H}}$, the initial (status quo) tariff level. This increases the severity of the information problem, in the sense that information about the opponent's type becomes more payoff-relevant. While the cooperative welfare $w(\delta)$ does not change, conceding unilaterally becomes less profitable $\left(w^{\mathrm{R}}\right.$ is strictly decreasing in $x^{\mathrm{H}}$ ); and keeping the status-quo tariffs when the other country concedes becomes more attractive, provided that $x_{\mathrm{H}}$ is not too large $\left(w^{\mathrm{N}}\right.$ is then

\footnotetext{
${ }^{10} \mathrm{An}$ interesting alternative interpretation of $\delta$ is as the probability that the trade relationship between the two countries will continue for another period. That is, it could be thought of as the probability that an event that would put the trade relationship at risk (e.g. a war, a severe economic downturn) does not happen. Both of these interpretations appear relevant for the early 1930s, the time of the Great Depression during which trade tensions ran extremely high and countries were unable to reach a cooperative trade agreement (see Table 1).

${ }^{11}$ The condition in Eq. (13) is derived in the proof of Proposition 5.
} 
strictly increasing in $\left.x^{\mathrm{H}}\right) .^{12}$ Under this last condition, therefore, a trade war and unilateral concessions are more likely to occur the more severe is the information problem.

Further results can be obtained by parameterizing the stage game. This can be done in various ways. Here we consider two examples of stage games, each of which exhibits features that appear interesting in light of Table 1: the use of tariffs or export subsidies to protect individual sectors. In order to economize on space, we move directly to a discussion of the results. ${ }^{13}$

In a static partial-equilibrium tariff game social welfare $w_{i}$ can be expressed indirectly as a function of tariff levels $x_{i}$ and the free-trade volume of trade $V^{\mathrm{f}}$, as shown in Bagwell and Staiger (1990). Given the stage-game welfare functions, we can compute $\bar{w}, w^{\mathrm{N}}$ and $w^{\mathrm{R}}$ as functions of the trade volume. If the initial tariff $x^{\mathrm{H}}$ is not too small, we find that immediate reciprocal concessions are more likely to occur the smaller is the underlying volume of trade in the sector. In sectors with a high potential trade volume, by contrast, conflict settlement is more likely to involve delay and unilateral concessions. The reason is that as the trade volume goes up, defection from a cooperative agreement becomes more profitable and the cooperative tariff level $\bar{x}$ has to rise to prevent defections. As a result, the cooperative welfare $\bar{w}$ increases more slowly with the trade volume than $w^{\mathrm{N}}$, provided that $x^{\mathrm{H}}$ is sufficiently large. Moreover, for large enough $x^{\mathrm{H}}, w^{\mathrm{N}}$ increases more quickly in trade volume than $w^{\mathrm{R}}$.

Finally, consider a two-step stage game in which governments first choose export subsidies to maximize producer surplus minus the subsidy payment, and then firms (one from each country) compete in the world market in a Cournot fashion (see Brander and Spencer, 1985 for a more general formulation). Letting $x_{i}$ denote the subsidy paid by the government of country $i$ to its firm, country I's welfare function can be expressed as $w_{\mathrm{I}}\left(x_{\mathrm{I}}, x_{\mathrm{II}}, c\right)$ where $c$ is the marginal production cost, assumed constant and identical across firms. Calculating the welfare terms that appear in Eq. (13), it can be shown that if status-quo subsidies are relatively small, immediate reciprocal concessions are more likely to occur the lower the marginal costs of the firms involved. On the other hand, when marginal costs are high, delay and unilateral concessions should occur more frequently. The reason for this result is the following: as $c$ rises, $\bar{w}$ and also $w^{\mathrm{R}}$ fall more quickly

\footnotetext{
${ }^{12}$ How $w^{\mathrm{N}}$ changes with $x^{\mathrm{H}}$ can easily be seen in Fig. 1. There, $x^{\mathrm{H}}$ has been drawn at a level at which any change in $x^{\mathrm{H}}$ would lower $w^{\mathrm{N}}$. To the left of this level $w^{\mathrm{N}}$ is strictly increasing in $x^{\mathrm{H}}$, to the right it is strictly decreasing.

${ }^{13} \mathrm{~A}$ more detailed version of this analysis is available from the authors upon request. The key step in this analysis is to explicitly compute $\bar{w}(\delta)$, the welfare in the symmetric undominated equilibrium of Agreement RR. This is accomplished by first solving for the lowest protection level that satisfies Eq. (4) with equality and then substituting the result into the stage-game welfare function. That is, we calculate $\bar{x}$ such that $w(\bar{x}, \bar{x})=(1-\delta) w_{i}\left(x_{i}^{*}(\bar{x}), \bar{x}\right)+\delta w$, and then determine $\bar{w}(\delta)=w(\bar{x}(\delta), \bar{x}(\delta))$.
} 
than $w^{\mathrm{N}}$, therefore the opportunity cost of waiting for the other country's concession tends to decrease, making both countries more eager to wait for their opponent to move.

\section{Conclusions}

The purpose of this paper was to develop a model that would allow us to examine two stylized facts regarding the settlement of trade disputes: delay in reaching agreement, and the occurrence of both reciprocal and unilateral concessions. Two crucial ingredients of our model were: (i) governments, at least initially, are uncertain about the objective functions of their opponents, i.e. about whether the other government would be willing to make a concession to end the dispute; (ii) agreements to end a conflict must be self-enforcing, i.e. they must be based on credible threats and promises.

The key to determine whether a conflict is ended immediately through reciprocal concessions or dragged out and/or settled through unilateral concessions is a comparison between a country's expected discounted welfare from making a concession, thus potentially reaching a cooperative agreement with the other country, and from waiting for one more period for a concession by its trading partner. Factors that make a cooperative agreement less profitable or harder to sustain make delay and unilateral concessions more likely. Among them are: low discount factors; a large underlying volume of trade in the disputed sector; and, in the case of a conflict over export subsidies, high (low) marginal costs when the status-quo subsidies are low (high). Most of these predictions of the model are testable and future empirical research is needed to check how they hold up to the data.

Several other extensions may also be of interest. To obtain more specific results for countries with asymmetric stage-game payoffs or asymmetric discount factors, one would need to find a reasonable focal point for Agreement RR, especially for situations in which free trade is not feasible. Existing bargaining solutions may not be useful here because they do not take into account that players may deviate from an agreement in order to enjoy asymmetric deviation gains. Such deviation gains, however, should influence the choice of the focal point. A potentially useful approach may be to combine elements from both noncooperative and cooperative game theory, as suggested by Harrington (1991) and Furusawa (1994). One could also relax the assumption of stationarity of the trading environment. This extension may provide an interesting way of addressing the question as to whether the formation of regional trading blocks impedes the process of multilateral trade liberalization. One of the key concerns here, expressed for example by Bagwell and Staiger (1993), is that regional trade agreements lead to trade diversion, which in turn may affect the countries' incentives to support freer multilateral trade. In 
the context of our model, if countries anticipate trade diversion to occur, the expected future gains from the potential types of agreements (RR, RN and NR) will be affected, which may thus have an effect on both the type of the multilateral agreement reached and delay before settling disputes. We intend to explore this issue further in the future.

\section{Acknowledgments}

We thank seminar participants at the universities of Bilkent, Indiana, Laval, Paris, Québec à Montreal, Wisconsin-Madison and audiences at the European Meetings of the Econometric Society, two referees and a co-editor for helpful comments and suggestions. Remaining errors are our own.

\section{Appendix A}

\section{Proof of Proposition 5}

The proof consists of deriving the best reply functions, which are then used in constructing the equilibria described in the proposition. Note that the best reply functions will have symmetric properties. Consider first country I. It has two choices in period one: it can set $\rho_{\mathrm{I}}^{1}=1$ and thus reveal its type, or it can choose to conceal its type in the first period $\left(\rho_{\mathrm{I}}^{1}=0\right)$. Suppose that country I sets $\rho_{\mathrm{I}}^{1}=1$. Then according to Proposition 4 two things can happen. If country II also concedes, $\rho_{\mathrm{II}}^{1}=1$, the game collapses to the RR-game; the countries behave as they do in the PBE of this game, which yields them both the average welfare $\bar{w}(\delta)$. If country II chooses $\rho_{\mathrm{II}}^{1}=0$, then the RN-game will be played, providing country I with a welfare of $w^{\mathrm{R}}$ each period. On the other hand, if country I selects $\rho_{\mathrm{I}}^{1}=0$, its welfare is determined as follows. If country II has conceded, then country I will choose $\left\{\rho_{\mathrm{I}}^{2}\right\}=\{0,0, \ldots\}$ for a gain of $w^{\mathrm{N}}$ each period (Agreement NR). Otherwise country I will concede in period two and obtain $w^{\mathrm{R}}$ after receiving a welfare of zero in the first period. Thus country I prefers $\rho_{\mathrm{I}}^{1}=1$ to $\rho_{\mathrm{I}}^{1}=0$ whenever

$$
\pi_{\mathrm{II}}^{1}\left(\frac{\bar{w}(\delta)}{1-\delta}\right)+\left(1-\pi_{\mathrm{II}}^{1}\right)\left(\frac{w^{\mathrm{R}}}{1-\delta}\right) \geq \pi_{\mathrm{II}}^{1}\left(\frac{w^{\mathrm{N}}}{1-\delta}\right)+\left(1-\pi_{\mathrm{II}}^{1}\right)\left(0+\frac{\delta w^{\mathrm{R}}}{1-\delta}\right),
$$

or

$$
\pi_{\mathrm{II}}^{1}\left(\bar{w}(\delta)-w^{\mathrm{N}}\right)+\left(1-\pi_{\mathrm{II}}^{1}\right) w^{\mathrm{R}}(1-\delta) \geq 0 .
$$

Clearly, if $\delta \geq \delta_{\mathrm{c}}$, Eq. (A.1) holds no matter the value of $\pi_{\mathrm{II}}^{1}$, which implies that country I chooses the first option mentioned above. Using the symmetry property, 
we can see that $\left\{\rho_{i}^{1}\right\}=\{1,1, \ldots\}, i=\mathrm{I}$,II, form a PBE if $\delta \geq \delta_{\mathrm{c}}$, which proves case (1).

Consider now the case $\delta<\delta_{\text {c }}$. Since $\bar{w}(\delta)-w^{N}<0$, the left-hand side of Eq. (A.1) must be decreasing in $\pi_{\mathrm{II}}^{1}$. Define the schedule $\bar{\pi}(\delta)$ by the function $\left(0, \delta_{\mathrm{c}}\right] \rightarrow[0,1]$, such that Eq. (A.1) holds with equality. Given $\delta<\delta_{\mathrm{c}}$, we obtain the equilibrium in case (1) if $\pi_{i}^{1} \leq \bar{\pi}(\delta)$ for $i=\mathrm{I}$,II. Inspection of Eq. (A.1) reveals that, for the case of asymmetric beliefs, $\pi_{i}^{1} \leq \bar{\pi}(\delta)<\pi_{j}^{1}$, the strategies described in the proposition form a PBE: Eq. (A.1) holds for country $j$, it therefore chooses $\left\{\rho_{j}^{1 *}\right\}=\{1,1, \ldots\}$ no matter what the strategy of country $i$. Given this strategy of country $j$, the best reply of country $i$ is to set $\left\{\rho_{i}^{1 *}\right\}=\{0,0, \ldots\}$ if its prior belief $\pi_{j}{ }^{1}$ is low enough. The postulated sequences of beliefs are consistent with the strategies. Finally, the non-existence of a pure concession strategy equilibrium if $\bar{\pi}(\delta)<\pi_{i}^{1}$ for $i=\mathrm{I}$,II, so that both countries are optimistic enough, can be checked similarly. Q.E.D.

\section{Proof of Proposition 6}

We know by Proposition 3 that the countries will surely reach an agreement if at least one country is of type $\mathrm{L}$. If an agreement is reached at date $T$, then at least one of the two beliefs at date $T$ must be less than or equal to $\bar{\pi}(\delta)$. So we consider the case $\pi_{\mathrm{I}}^{T}<\bar{\pi}(\delta)<\pi_{\mathrm{II}}^{T}$ in which, by Proposition 5, country I's optimal strategy in period $T$ is $\rho_{\mathrm{I}}^{T *}=0$ and country II's is $\rho_{\mathrm{II}}^{T *}=1$ (the proofs for the cases $\pi_{\mathrm{II}}^{T}<\bar{\pi}(\delta)<\pi_{\mathrm{I}}^{T}$ and $\pi_{i}^{T}<\bar{\pi}(\delta)$ for $i=\mathrm{I}$,II use similar arguments).

Claim 1: $0<\rho_{i}^{T-1} *<1$.

Proof. If $\rho_{\mathrm{I}}^{T-1}=1$, then an agreement would be reached at date $T-1$, which contradicts our assumption. On the other hand, if $\rho_{\mathrm{I}}^{T-1}=0$, then $\pi_{\mathrm{I}}^{T-1}=\pi_{\mathrm{I}}^{T}$. But since $\pi_{\mathrm{I}}^{T}<\bar{\pi}(\delta)$, the optimal strategy of country II must be $\pi_{\mathrm{II}}^{T-1}=1$, leading to an agreement at date $T-1$, a contradiction. Therefore, $0<\rho_{\mathrm{I}}^{T-1} *<1$. Similar arguments can be used to show that $0<\rho_{\mathrm{II}}^{T-1 *}<1$.

Claim 2: $\pi_{\mathrm{I}}^{T-1}>\bar{\pi}(\delta)>\pi_{\mathrm{I}}^{T}$.

Proof. $0<\rho_{\mathrm{I}}^{T-1} *<1$ implies $\pi_{\mathrm{I}}^{T}<\pi_{\mathrm{I}}^{T-1}$ through Bayes' rule. Finally, if $\pi_{\mathrm{I}}^{T-1}<\pi(\delta)$, then $\rho_{\mathrm{II}}^{T-1}=1$, which contradicts claim 1 .

At the beginning of period $T$ (before concession strategies are observed), country I's and country II's average expected welfare given the proposed optimal period $T$ strategies are respectively given by

$$
(1-\delta) V_{\mathrm{I}}^{T}=\pi_{\mathrm{II}}^{T} w^{\mathrm{N}}+\left(1-\pi_{\mathrm{II}}^{T}\right) \delta w^{\mathrm{R}} \text { and }(1-\delta) V_{\mathrm{II}}^{T}=w^{\mathrm{R}} .
$$

Let us now move backwards to period $T-1$. By claims 1 and 2, we must have $\pi_{i}^{T-1}>\bar{\pi}(\delta)$ for both countries, which, by Proposition 5, implies that the equilibrium strategies cannot be pure. However, an equilibrium in completely mixed strategies exists; we construct this equilibrium below. The average welfares 
in period $T-1$ associated with pure concession strategies are as follows. Playing $\rho_{\mathrm{II}}^{T-1}=1$ yields country II

$$
\pi_{\mathrm{I}}^{T-1} \rho_{\mathrm{I}}^{T-1} \bar{w}(\delta)+\left(1-\pi_{\mathrm{I}}^{T-1} \rho_{\mathrm{I}}^{T-1}\right) w^{\mathrm{R}},
$$

while $\rho_{\mathrm{II}}^{T-1}=0$ yields

$$
\pi_{\mathrm{I}}^{T-1} \rho_{\mathrm{I}}^{T-1} w^{\mathrm{N}}+\left(1-\pi_{\mathrm{I}}^{T-1} \rho_{\mathrm{I}}^{T-1}\right) \delta w^{\mathrm{R}},
$$

given that $\rho_{\mathrm{I}}^{T *}=0$ and $\rho_{\mathrm{II}}^{T *}=1$. Similarly,

$$
\pi_{\mathrm{II}}^{T-1} \rho_{\mathrm{II}}^{T-1} \bar{w}(\delta)+\left(1-\pi_{\mathrm{II}}^{T-1} \rho_{\mathrm{II}}^{T-1}\right) w^{\mathrm{R}}
$$

is what country I would expect on average from $\rho_{\mathrm{I}}^{T-1}=1$, and using Eqs. (A.2),

$$
\pi_{\mathrm{II}}^{T-1} \rho_{\mathrm{II}}^{T-1} w^{\mathrm{N}}+\left(1-\pi_{\mathrm{II}}^{T-1} \rho_{\mathrm{II}}^{T-1}\right) \delta\left(\pi_{\mathrm{II}}^{T} w^{\mathrm{N}}+\left(1-\pi_{\mathrm{II}}^{T}\right) \delta w^{\mathrm{R}}\right),
$$

from playing $\rho_{\mathrm{I}}^{T-1}=0$.

Claim 3: $\delta\left[\pi_{\text {II }}^{T} w^{\mathrm{N}}+\left(1-\pi_{\mathrm{II}}^{T}\right) \delta w^{\mathrm{R}}\right]<w^{\mathrm{R}}$.

Proof. Assume the contrary. $\delta<\delta_{\text {c }}$ implies $\bar{w}(\delta)<w^{\mathrm{N}}$, and we have the expression in Eq. (A.6) exceeding Eq. (A.5). The optimum strategy for country I is then $\rho_{\mathrm{I}}^{T-1}=0$. But since $\rho_{\mathrm{I}}^{T *}=0$ too, country II would be better off by setting $\rho_{\mathrm{II}}^{T-1}=1$ (conceding in period $T-1$ ), and an agreement would be reached, which contradicts claim 1 .

Now, given the result in claim 3 and $\pi_{i}^{T-1}>\bar{\pi}(\delta)$ for $i=\mathrm{I}, \mathrm{II}$, there must exist numbers $0<\rho_{i}^{T-1} *<1$, such that

$$
\begin{aligned}
& \rho_{\mathrm{I}}^{T-1} *=\left(\frac{1}{\pi_{\mathrm{I}}^{T-1}}\right) /\left(1+\frac{w^{\mathrm{N}}-\bar{w}(\delta)}{(1-\delta) w^{\mathrm{R}}}\right), \quad \text { and } \\
& \rho_{\mathrm{II}}^{T-1} *=\left(\frac{1}{\pi_{\mathrm{II}}^{T-1}}\right) /\left(1+\frac{w^{\mathrm{N}}-\bar{w}(\delta)}{w^{\mathrm{R}}-\delta\left(\pi_{\mathrm{II}}^{T} w^{\mathrm{N}}+\left(1-\pi_{\mathrm{II}}^{T}\right) \delta w^{\mathrm{R}}\right)}\right) .
\end{aligned}
$$

These strategies are determined using Eqs. (A.3) and (A.4) and Eqs. (A.5) and (A.6), and are unique. Thus the respective welfares of the two countries, discounted to $T-1$, are $V_{\mathrm{I}}^{T-1}=\rho_{\mathrm{I}}^{T-1} *$ (Eq. (A.5)) $+\left(1-\rho_{\mathrm{I}}^{T-1} *\right)$ (Eq. (A.6)) and $V_{\mathrm{II}}^{T-1}=\rho_{\mathrm{II}}^{T-1} *$ (Eq. (A.3)) $+\left(1-\rho_{\mathrm{II}}^{T-1} *\right)$ (Eq. (A.4)). Clearly, $\rho_{\mathrm{I}}^{T-1} *$ and $\rho_{\mathrm{II}}^{T-1} *$ are best replies to each other, and beliefs are consistent; we have constructed the portion of the PBE path for the periods $T$ and $T-1$. Given $V_{\mathrm{I}}^{T-1}$ and $V_{\mathrm{II}}^{T-1}$, we can proceed to period $T-2$ and determine the optimal (mixed) concession strategies, using Bayes' rule for updating beliefs as we did for period $T-1$. Carrying this process inductively until period one should lead us to the initial conditions described by $\pi_{\mathrm{I}}^{1}, \pi_{\mathrm{II}}^{1}$, and $\delta<\delta_{\mathrm{c}}$. The concession game ending at period $T$ is a finite game, thus the number of Nash equilibria must be odd. Since no equilibrium in pure concession strategies exists, this number is equal to one. Q.E.D. 


\section{References}

Bagwell, K. and R. Staiger, 1990, A theory of managed trade, American Economic Review 80, 779-795.

Bagwell, K. and R. Staiger, 1993, Multilateral tariff cooperation during the formation of regional free trade areas, NBER Working Paper No. 4364.

Brander, J.A. and B.J. Spencer, 1985, Export subsidies and international market share rivalry, Journal of International Economics 18, 83-100.

Chatterjee, K. and L. Samuelson, 1987, Bargaining with two-sided incomplete information: An infinite horizon model with alternating offers, Review of Economic Studies 54, 175-192.

Conybeare, J.A.C., 1987, Trade wars (Columbia University Press, New York).

Cooter, R. and D. Rubinfield, 1989, Economic analysis of legal disputes and their resolution, Journal of Economic Literature 27, 1067-1097.

Dixit, A., 1987, Strategic aspects of trade policy, in: T.F. Bewley, ed., Advances in economic theory (Cambridge University Press, New York) 329-362.

Feenstra, R.C. and T.R. Lewis, 1991, Negotiated trade restrictions with private political pressure, Quarterly Journal of Economics 106, 1287-1307.

Fudenberg, D. and J. Tirole, 1991, Game theory (MIT Press, Cambridge, MA).

Furusawa, T., 1994, The negotiation of sustainable tariffs, mimeo, University of Wisconsin-Madison.

Grossman, G. and E. Helpman, 1993, Trade wars and trade talks, Journal of Political Economy 103, $675-708$.

Harrington, J.E., 1991, The determination of price and output quotas in a heterogeneous cartel, International Economic Review 32, 767-792.

Jensen, R. and M. Thursby, 1988, Tariffs under political uncertainty, mimeo, Purdue University.

Jensen, R. and M. Thursby, 1990, Tariffs with private information and reputation, Journal of International Economics 29, 43-67.

Johnson, H.G., 1953/54, Optimum tariffs and retaliation, Review of Economic Studies 21, $142-153$.

Ludema, R.D., 1991, Optimal international trade agreements and dispute settlement procedures, Research Report 9101, University of Western Ontario.

Mayer, W., 1981, Theoretical considerations on negotiated tariff adjustments, Oxford Economic Papers 33, $135-153$.

McMillan, J., 1986, Game theory in international economics (Harwood Academic Publishers, Chur).

McMillan, J., 1992, Games, strategies and managers (Oxford University Press, Oxford).

Riezman, R., 1982, Tariff retaliation from a strategic viewpoint, Southern Economic Journal 48, 538-593.

Riezman, R., 1991, Dynamic tariffs with asymmetric information, Journal of International Economics 30, 267-283.

Staiger, R.W., 1994, A theory of gradual trade liberalization, NBER Working Paper No. 4620.

Tirole, J., 1988, The theory of industrial organization (MIT Press, Cambridge, MA). 